\title{
Digestibilidade aparente do farelo de palmiste em tambaqui (Colossoma macropomum)
}

\author{
[Apparent digestibility of palm kernel meal to tambaqui (Colossoma macropomum)] \\ R.S. Silva ${ }^{1}$, R.V.E. Santo ${ }^{1}$, A.V.C. Barbosa ${ }^{2}$, M.A.S. Santos ${ }^{2}$, \\ R.O. Corrêa $a^{3}$, H. Martins Júnior ${ }^{3}$, J.B. Lourenço Júnior ${ }^{4}$ \\ ${ }^{1}$ Instituto Federal de Educação, Ciência e Tecnologia do Pará - Belém, PA \\ ${ }^{2}$ Universidade Federal Rural da Amazônia - Belém, PA \\ ${ }^{3}$ Embrapa Amazônia Oriental - Belém, PA \\ ${ }^{4}$ Universidade Federal do Pará - Castanhal, PA
}

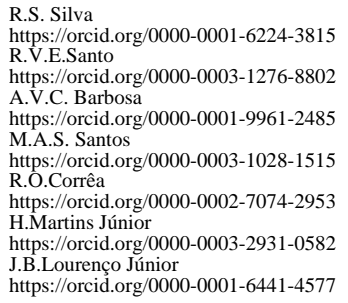

RESUMO

O objetivo deste trabalho foi determinar a digestibilidade do farelo de palmiste (Elaeis guineensis) para o tambaqui (Colossoma macropomum), em duas classes de peso: 1 (210 alevinos de 4,45 1 , 18g) e 2 (54 juvenis de $115,91 \pm 4,01 \mathrm{~g}$ ). Os coeficientes de digestibilidade aparente (CDA) da matéria seca, proteína bruta e energia bruta do farelo de palmiste foram avaliados pela metodologia de substituição da dieta referência, utilizando-se $0,1 \%$ de óxido crômico como indicador externo. Os dados foram analisados pelo teste t de Student, a 5\% de probabilidade. Os CDAs da matéria seca, proteína bruta e energia bruta do ingrediente foram iguais $(\mathrm{P}>0,05)$ nas classes de peso avaliadas. Os CDAs observados nas classes 1 e 2 , respectivamente, foram: matéria seca $(17,52 \%$ e $20,75 \%)$, proteína bruta $(62,83 \%$ e 63,75\%) e energia bruta $(14,16 \%$ e $22,43 \%)$. A capacidade do tambaqui para digerir os nutrientes do farelo de palmiste não foi influenciada pelo peso corporal, e o aproveitamento satisfatório da proteína $(63,29 \%)$ faz desse ingrediente uma potencial fonte alternativa de proteína em dietas para a espécie.

Palavras-chave: piscicultura, onívoro, coproduto, valor nutritivo

\section{ABSTRACT}

The objective of this work was to determine the digestibility of palm kernel meal (Elaeis guineensis) in tambaqui (Colossoma macropomum), in two weight classes: 1 (210 fingerlings of 4.45 $\pm 1.18 \mathrm{~g}$ ) and 2 (54 juveniles of $115.91 \pm 4.01 \mathrm{~g})$. The apparent digestibility coefficients $(A D C)$ of dry matter, crude protein and crude energy of the palm kernel meal were evaluated by the substitution of the reference diet methodology, using $0.1 \%$ chromic oxide as an external indicator. Data were analyzed by Student's t-test at $5 \%$ probability. The dry matter, crude protein and crude energy ADCs of the ingredient were the same $(P>0.05)$ in the weight classes evaluated. The ADCs observed in classes 1 and 2, respectively, were: dry matter (17.52\% and 20.75\%), crude protein (62.83\% and $63.75 \%)$ and crude energy $(14.16 \%$ and $22.43 \%)$. The ability of tambaqui to digest the nutrients of palm kernel meal was not influenced by body weight, and satisfactory protein utilization (63.29\%) makes this ingredient a potential alternative source of protein in diets for the species.

Keywords: pisciculture, omnivorous, coproduct, nutritive value

\section{INTRODUÇÃO}

O tambaqui (Colossoma macropomum, Cuvier, 1818) é a principal espécie nativa criada no Brasil, com boas características de produção e capacidade de digerir proteína animal e vegetal (Rodrigues, 2014). Nas criações intensivas dessa espécie, as despesas com ração podem representar até $60 \%$ do custo de produção (Izel e

Recebido em 30 de julho de 2018

Aceito em 8 de janeiro de 2019

E-mail: rayette.silva@ifpa.edu.br
Melo, 2004), o que tem estimulado a busca por ingredientes regionais alternativos, que subsidiem a produção de rações de qualidade a menor custo.

Nesse contexto, um grande volume de coprodutos da agroindústria da palma (Elaeis guineensis) está disponível no mercado nacional, uma vez que o Brasil é o nono produtor mundial dessa cultura. Do mesocarpo carnoso do fruto é 
extraído o óleo de palma e da amêndoa, o óleo de palmiste, cuja obtenção, por extração mecânica, gera como resíduo a torta e, quando feita por solvente, o farelo (Heuzé et al., 2016). O farelo de palmiste pode ser utilizado como fonte proteica ou energética, apesar de ter deficiência em lisina e metionina e elevado teor de fibra bruta (Hertrampf e Piedad-Pascual, 2000). Pesquisas sobre a digestibilidade de coprodutos do palmiste em peixes vêm sendo realizadas (Oliveira et al., 1997; Ramos et al., 2012; Vásquez-Torres et al., 2013; Obirikorang et al., 2015), no entanto informações sobre a digestibilidade do farelo de palmiste para espécies nativas, como o tambaqui, ainda são escassas.

A determinação dos coeficientes de digestibilidade aparente (CDA) de ingredientes permite avaliar seu valor biológico e formular dietas eficientes e nutricionalmente completas, reduzindo o potencial poluente das rações no ambiente de criação, condição fundamental para garantir o bem-estar animal e ganhos em produtividade (Nutrient..., 2011; Buzzolo et al., 2018). No entanto, a digestibilidade dos nutrientes pode ser influenciada pelo estágio do ciclo de vida em que o animal se encontra (Nutrient..., 2011), sendo importante considerar essa condição ao formular rações específicas visando ao máximo desempenho e ao menor desperdício. Dessa forma, por não haver informações sobre a digestibilidade do farelo de palmiste para o tambaqui, o objetivo desta pesquisa foi determinar seus valores digestíveis para duas classes de peso vivo dessa espécie.

\section{MATERIAL E MÉTODOS}

Os procedimentos experimentais foram aprovados pela Comissão de Ética do Uso de Animais (Ceua) da Embrapa Amazônia Oriental (Protocolo $\mathrm{n}^{\mathrm{o}}$ 006/2016). O delineamento experimental foi inteiramente ao acaso, com dois tratamentos (classes de peso 1 e 2) e três repetições. Os peixes foram aclimatados ao experimento por 15 dias e distribuídos nas unidades experimentais em triplicata, sendo 35 peixes por caixa para a classe de peso 1 $(4,45 \pm 1,18 \mathrm{~g})$ e nove peixes por caixa para a classe de peso $2(115,91 \pm 4,01 \mathrm{~g})$. A alimentação foi feita quatro vezes ao dia, até saciedade aparente. A dieta referência foi formulada (Tab. 1) para atender à exigência nutricional dos peixes (Izel e Melo, 2004) e a teste foi preparada com $69,9 \%$ da dieta referência e $30 \%$ do farelo de palmiste.

Tabela 1. Composição percentual e valor nutricional da dieta referência e do ingrediente

\begin{tabular}{|c|c|c|}
\hline Ingredi & & \\
\hline Farelo de soja & 48,00 & \\
\hline Milho & 25,00 & \\
\hline Farinha de peixe & 21,20 & \\
\hline Óleo de soja & 2,60 & \\
\hline L-lisina & 1,30 & \\
\hline DL-metionina & 0,30 & \\
\hline Premix $^{1}$ & 0,50 & \\
\hline Fosfato bicálcico & 1,00 & \\
\hline Composição (\%) & & Farelo de palmiste \\
\hline Matéria seca & 92,25 & 87,03 \\
\hline Proteína bruta & 35,48 & 14,08 \\
\hline Extrato etéreo & 5,52 & 1,52 \\
\hline Matéria mineral & 9,74 & 3,88 \\
\hline Fibra bruta & - & 21,22 \\
\hline Fibra em detergente ácido & 8,22 & - \\
\hline Fibra em detergente neutro & 40,66 & - \\
\hline Energia bruta $\left(\mathrm{kcal} \mathrm{kg}^{-1}\right)$ & $4.429,0$ & $4.125,5$ \\
\hline
\end{tabular}


Os ingredientes foram moídos $(0,5 \mathrm{~mm})$ e homogeneizados, sendo a mistura peletizada em matriz de $2 \mathrm{~mm}$, para a classe 1 , e de $6 \mathrm{~mm}$, para a classe 2 . A secagem foi feita a $55^{\circ} \mathrm{C}$, por $24 \mathrm{~h}$, e as rações foram armazenadas em freezer ($20^{\circ} \mathrm{C}$ ), até sua utilização. A digestibilidade foi feita por meio do método indireto, utilizando óxido de crômio-III $\left(\mathrm{Cr}_{2} \mathrm{O}_{3}\right)$ como marcador inerte $(0,1 \%)$, em sistema modificado do tipo Guelph (Nutrient..., 2011). O material fecal coletado foi seco $\left(55^{\circ} \mathrm{C}\right)$ por $24 \mathrm{~h}$, macerado e armazenado em freezer $\left(-20^{\circ} \mathrm{C}\right)$, até a realização das análises. Coeficientes de digestibilidade aparente das dietas foram estimados por Cho e Slinger (1979): CDA N(\%) $=100-100 \mathrm{x}$ $\left[\left(\% \mathrm{Cr}_{2} \mathrm{O}_{3} \mathrm{R} / \% \mathrm{Cr}_{2} \mathrm{O}_{3} \mathrm{~F}\right) \times(\% \mathrm{NF} / \% \mathrm{NR})\right]$, em que: $\% \mathrm{Cr}_{2} \mathrm{O}_{3} \mathrm{R}=$ percentual de óxido de crômioIII na ração; $\% \mathrm{Cr}_{2} \mathrm{O}_{3} \mathrm{~F}=$ percentual de óxido de crômio-III nas fezes; $\% \mathrm{NR}=$ percentual de nutriente na ração; e \% NF = percentual nutriente nas fezes.

Coeficientes de digestibilidade aparente dos nutrientes do farelo de palmiste foram estimados pela seguinte equação (Bureau et al., 1999): CDA I $(\%)=$ CDADt $+($ CDADt - CDADr $) \mathrm{x}$ $(0,69 \times \mathrm{NDr} / 0,3 \times \mathrm{N}$ I), em que: CDA I = coeficiente de digestibilidade aparente do nutriente no ingrediente testado; CDA Dt = coeficiente de digestibilidade aparente do nutriente na dieta teste; CDA Dr = coeficiente de digestibilidade aparente do nutriente na dieta referência; e NDr e N I = teor de nutrientes contidos na dieta referência e no ingrediente testado.

Foram monitorados, semanalmente, oxigênio dissolvido $\left(\mathrm{mg} \mathrm{L}^{-1}\right), \mathrm{pH}$, amônia total $\left(\mathrm{mg} \mathrm{L}^{-1}\right)$, nitrito $\left(\mathrm{mg} \mathrm{L}^{-1}\right)$ e nitrato $\left(\mathrm{mg} \mathrm{L}^{-1}\right)$. A temperatura da água foi mantida a $28,7 \pm 0,8^{\circ} \mathrm{C}$. As composições químicas do farelo de palmiste (Tab. 2), das dietas e das fezes foram determinadas segundo metodologia da AOAC (Official..., 2012), para matéria seca (MS), proteína bruta $(\mathrm{PB})$, extrato etéreo (EE), matéria mineral (MM), conforme Silva e Queiroz (2002), para fibra bruta $(\mathrm{FB})$, fibra em detergente ácido (FDA), fibra em detergente neutro (FDN) e óxido de crômio-III $\left(\mathrm{Cr}_{2} \mathrm{O}_{3}\right)$ e a energia bruta (EB) determinada em bomba calorimétrica. Os dados foram analisados com auxílio do software $\mathrm{SAS}^{\circledR}(2017)$, por meio do teste $\mathrm{t}$ de Student, a $5 \%$ de probabilidade.

\section{RESULTADOS E DISCUSSÃO}

Não foi registrada mortalidade, e as variáveis físicas e químicas da água não sofreram alterações durante o período experimental $\left(\mathrm{OD}=7,7 \pm 0,7 \mathrm{mg} \mathrm{L}^{-1}, \mathrm{pH}=5,1 \pm 0,9\right.$, amônia total $=1,6 \pm 1,1 \mathrm{mg} \mathrm{L}^{-1}$, nitrito $=0,01 \pm 0,02 \mathrm{mg} \mathrm{L}^{-1}$, nitrato $\left.=0,13 \pm 0,22 \mathrm{mg} \mathrm{L}^{-1}\right)$, estando adequadas ao bem-estar dos peixes (Aride et al., 2007). Apesar de o tamanho do peixe ser um dos fatores que interferem na digestibilidade (Nutrient..., 2011), os CDAs do farelo de palmiste para matéria seca (MS), proteína bruta (PB) e energia bruta (EB) não diferiram entre as classes de peso avaliadas (Tab. 2; P>0,05). Ramos et al. (2012) também não encontraram diferença nos CDAs da torta de palmiste, em duas classes de tamanho (200 e 300g) de tilápias-do-nilo (Oreochromis niloticus), ao contrário de Quintero-Pinto et al. (2017), que, ao trabalharem com essa mesma espécie $(25,250$ e $500 \mathrm{~g})$, observaram que os peixes maiores aproveitaram melhor os nutrientes de alimentos de origem vegetal.

Tabela 2. Coeficientes de digestibilidade aparente (média \pm desvio-padrão) da matéria seca (MS), proteína bruta $(\mathrm{PB})$ e energia bruta (EB) do farelo de palmiste e respectivos valores digestíveis para tambaqui nas classes de peso $1(4,45 \pm 1,18 \mathrm{~g})$ e $2(115,91 \pm 4,01 \mathrm{~g})$

\begin{tabular}{cccccc}
\hline$(\%)$ & CDA 1 & CDA 2 & VB & VD 1 & VD 2 \\
\hline Matéria seca & $17,52 \pm 3,00 \mathrm{a}$ & $20,75 \pm 5,08 \mathrm{a}$ & 87,03 & 15,25 & 18,06 \\
Proteína bruta & $62,83 \pm 1,54 \mathrm{a}$ & $63,75 \pm 3,88 \mathrm{a}$ & 14,08 & 8,85 & 8,98 \\
Energia bruta & $14,16 \pm 2,57 \mathrm{a}$ & $22,43 \pm 3,37 \mathrm{a}$ & 4125,5 & 584,17 & 925,35 \\
\hline
\end{tabular}

Letras iguais na linha indicam que não existe diferença estatística significativa entre os tratamentos $(\mathrm{P}>0,05) . \mathrm{CDA}=$ coeficiente de digestibilidade aparente; $\mathrm{VB}=$ valor bruto; $\mathrm{VD}=$ valor digestível.

O farelo de palmiste possui $12,8 \%$ de lignina (Heuzé et al., 2016) e elevada concentração de fibra bruta (Tab. 2), em geral indigeríveis para a maioria dos peixes (Nutrient..., 2011;
Obirikorang et al., 2015; Buzzolo et al., 2018). Sabe-se que altas concentrações de fibra insolúvel aceleram o trânsito alimentar no intestino, afetando negativamente a absorção de 
nutrientes (Enes et al., 2011). No farelo de palmiste, mais de $81 \%$ dos carboidratos totais correspondem aos polissacarídeos não amiláceos - PNAs (Knudsen, 1997), dos quais cerca de 96\% estão na forma insolúvel (Abdollahi et al., 2015) e foram relacionados à piora na digestibilidade de dietas para tambaquis (Silva et al., 2003). Isso acontece porque, em peixes e em outros monogástricos, b-glucanases ou bxilanases, enzimas que degradam esses carboidratos, são escassas ou inexistentes (Kuz'mina, 1996), impedindo seu uso como fonte de energia (Sinha et al., 2011; Nutrient..., 2011).

Entretanto, a fibra insolúvel tem pouca interferência na digestibilidade da proteína, quando comparada à solúvel (Nutrient..., 2011), o que provavelmente explica os CDAs da proteína terem sido os mais elevados entre as frações analisadas (Tab. 2). Os CDAs-PB determinados (Tab. 2) foram superiores aos registrados para tilápia, 61,1\% (Obirikorang et $a l ., 2015)$, e inferiores aos CDA-PB da torta de palmiste para pirapitinga (Piaractus brachyomus), 90,6\% (Vásquez-Torres et al., 2013), tilápia, 80\% (Ramos et al., 2012), e pacu (P. mesopotamicus), 75,76\% (Oliveira et al., 1997).

A fibra insolúvel, em níveis superiores a $10 \%$, impacta negativamente a digestibilidade da matéria seca e da energia bruta (Nutrient...., 2011). Uma relação negativa entre o teor de fibra do ingrediente e a digestibilidade aparente da MS e da EB foi demonstrada para o híbrido tambatinga (Bicudo et al., 2018) e para a tilápia (Guimarães et al., 2012). Os CDAs-MS obtidos, provavelmente, foram prejudicados pelos altos níveis de PNAs, como já relatado para o tambaqui (Guimarães et al., 2014). Os valores encontrados foram inferiores aos registrados em outras espécies onívoras com coprodutos do palmiste (Oliveira et al., 1997; Ramos et al., 2012; Vásquez-Torres et al., 2013; Obirikorang et al., 2015).

Os CDAs-EB da torta de palmiste para tilápia (Ramos et al., 2012; Obirikorang et al., 2015) e pirapitinga (Vásquez-Torres et al., 2013) variaram de 47,70 a $75,14 \%$, sendo superiores aos obtidos nesta pesquisa (Tab. 2). Segundo Soares et al. (2017), menores teores de EE correspondem a menores valores energéticos digestíveis, o que poderia explicar a menor digestibilidade energética obtida com o farelo em comparação a estudos com a torta de palmiste, pois, enquanto o farelo possui apenas $1,52 \% \mathrm{EE}$ (Tab. 1), a torta tem 9,2\% EE (Heuzé et al., 2016), podendo chegar a concentrações mais altas, dependendo do equipamento utilizado na prensagem. Esse efeito da quantidade de EE na digestibilidade da energia provavelmente se dá porque, entre os combustíveis metabólicos para obtenção de energia pelos peixes, o EE é o que apresenta maior valor calórico $\left(9,44 \mathrm{cal} \mathrm{g}^{-1} \mathrm{~EB}\right)$, em comparação aos carboidratos $\left(4,11 \mathrm{cal} \mathrm{g}^{-1} \mathrm{~EB}\right)$ e às proteínas $\left(5,64 \mathrm{cal} \mathrm{g}^{-1} \mathrm{~EB}\right)$ (Nutrient..., 2011). Além disso, os PNAs têm relação direta com a digestibilidade de energia, por terem capacidade de se ligar aos lipídios da dieta, o que reduz sua absorção no intestino (Nutrient..., 2011). Overland et al. (2009) sugerem que os PNAs dos alimentos reduzem a absorção de EE por perturbarem a formação de micelas no trato gastrointestinal de salmonídeos. A presença e a quantidade de PNAs nos alimentos também foram relacionadas aos menores valores de digestibilidade energética para tambaquis (Guimarães et al., 2014; Buzzolo et al., 2018).

De forma geral, as divergências encontradas entre os CDAs obtidos nesta pesquisa e os descritos na literatura para outras espécies podem estar associadas a diferenças no protocolo experimental e à diferente composição química da torta e do farelo de palmiste. O farelo, devido à eficiência de extração do óleo por solvente, possui mais fibra e menos $\mathrm{EE}$, quando comparado à torta (Heuzé et al., 2016). Destacam-se, ainda, as particularidades das espécies, pois, embora pacu, pirapitinga e tambaqui sejam espécies do mesmo grupo filogenético e tenham anatomia do trato gastrointestinal similar, parecem digerir os nutrientes de forma diferente.

A qualidade da proteína dos alimentos é o fator que mais afeta o desempenho dos peixes (Kleemann et al., 2009) e, considerando que o aproveitamento da proteína do farelo de palmiste (média de 63,29\%) foi satisfatório, é possível recomendá-lo como uma fonte proteica alternativa em dietas para tambaquis. Ressaltase, no entanto, a necessidade de pesquisas futuras para avaliar técnicas de processamento no coproduto (físicas, químicas e/ou enzimáticas) que reduzam o teor de fibra e extraiam e/ou 
inativem fatores antinutricionais, com a finalidade de aumentar a disponibilidade de carboidratos (PNAs), poupando o uso preferencial das proteínas como fonte de energia (Nutrient..., 2011; Enes et al., 2011).

\section{CONCLUSÕES}

O peso corporal $(4,45 \pm 1,18 \mathrm{~g}$ e $115,91 \pm 4,01 \mathrm{~g})$ representativo de diferentes estágios do ciclo de vida do tambaqui não interferiu em sua capacidade de digerir o farelo de palmiste. $\mathrm{O}$ aproveitamento da proteína foi considerado satisfatório $(63,29 \%)$, o que faz desse ingrediente uma potencial fonte alternativa de proteína em rações para a espécie.

\section{AGRADECIMENTOS}

Ao CNPq, por financiar o Projeto 468046/20143; ao PPGCAN- UFPA/Embrapa/UFRA; à CAPES; à Estação Experimental de Piscicultura da Embrapa Amazônia Oriental; à Ajinomoto Animal Nutrition Group.

\section{REFERÊNCIAS}

ABDOLLAHI, M.R.; HOSKING, B.; RAVINDRAN, V. Nutrient analysis, metabolizable energy and ileal amino acid digestibility of palm kernel meal for broilers. Anim. Feed Sci.Technol., v.206, p.119-125, 2015.

ARIDE, P.H.R.; ROUBACH, R.; VAL, A.L. Tolerance response of tambaqui Colossoma macropomum (Cuvier) to water pH. Aquac. Res., v.38, p.588-594, 2007.

BICUDO, A.J.A.; ARAÚJO, T.A.T.; BRAGA, L.G.T. et al. Apparent digestibility of conventional and alternative feedstuffs by hybrid tambacu juveniles. An. Acad. Bras. Cienc., v.90, p.471-478, 2018.

BUREAU, D.P.; HARRIS, A.M.; CHO, C.Y. Apparent digestibility of rendered animal protein ingredients for rainbow trout (Oncorhynchus mykiss). Aquaculture, v.180, p.345-358, 1999.

BUZZOLO, H.; NASCIMENTO, T.M.T.; SANDRE, L.C.G. et al. Apparent digestibility coefficients of feedstuff used in tambaqui diets. Bol. Inst. Pesca, v.44, p.316-322, 2018.
CHO, C.Y.; SLINGER, S.I. Apparent digestibility measurement in feedstuff for rainbow trout. In: HALVER, J.E.; TIEWS, K. (Eds.). Finfish nutrition and fish feed technology. Berlin: Heenemam, 1979. v.2, p.239-247.

ENES, P.; PANSERAT, S.; KAUSHIK, S.; OLIVA-TELES, A. Dietary carbohydrate utilization by European sea bass (Dicentrarchus labrax L.) and gilthead sea bream (Sparus aurata L.) juveniles. Rev. Fish. Sci., v.19, p.201-215, 2011.

GUIMARÃES, I.G.; MIRANDA, E.C.; ARAÚJO, J.G. Coefficients of total tract apparent digestibility of some feedstuffs for Tambaqui (Colossoma macropomum). Anim. Feed Sci. Technol., v.188, p.150-155, 2014.

GUIMARÃES, I.G.; PEZZATO, L.E.; BARROS, M.M.; FERNANDES, R.N. Apparent nutrient digestibility and mineral availability of protein-rich ingredients in extruded diets for Nile tilapia. Rev. Bras. Zootec., v.41, p.1801-1808, 2012.

HERTRAMPF, J.W.; PIEDAD-PASCUAL, F. Handbook on ingredients for aquaculture feeds. Dordrecht: Kluwer Academic Publishers, 2000. 573p.

HEUZÉ, V.; TRAN, G.; SAUVANT, D. et al. Palm kernel meal. In: HEUZÉ, V.; GILLES, T.; HÉLÉNE, T. Feedipedia: animal feed resources information system. Paris: AFZ/CIRAD, 2016. $15 \mathrm{p}$.

IZEL, A.C.U.; MELO, L.A.S. Criação de tambaqui (Colossoma macropomum) em tanques escavados no estado do Amazonas. Manaus: Embrapa Amazônia Ocidental, 2004. 19p.

KLEEMANN, G.K.; BARROS, M.M.; PEZZATO, L.E. Valor nutricional do farelo de algodão para a tilápia do nilo (Oreochromis niloticus). Acta Sci. Anim. Sci., v.31, p.87-94, 2009.

KNUDSEN, K.E.B. Carbohydrate and lignin contents of plant materials used in animal feeding. Anim. Feed Sci. Technol., v.67, p.319338, 1997.

KUZ'MINA, V.V. Influence of age on digestive enzyme activity in some freshwater teleosts. Aquaculture, v.148, p.25-37, 1996. 
NUTRIENT requirement of fish and shrimp. Washington: National Academic Press, 2011. 392p.

OBIRIKORANG, K.A.; AMISAH, S.; AGBO, N.W. et al. Evaluation of locally-available agroindustrial byproducts as partial replacements to fishmeal in diets for Nile Tilapia (Oreochromis niloticus) production in Ghana. J. Anim. Res. Nutr., v.1, p.1-9, 2015.

OFFICIAL methods of analysis. 19.ed. Gaithersburg: Association of Official Analytical Chemists International, 2012. 3000p.

OLIVEIRA, A.C.B.; CANTELMO, O.A.; PEZZATO, L.E. et al. Coeficiente de digestibilidade da torta de dendê e do farelo de coco em pacu (Piaractus mesopotamicus). Rev. Unimar, v.19, p.897-903, 1997.

OVERLAND, M.; SØRENSEN, M.; STOREBAKKEN, T. et al. Pea protein concentrates substituting fish meal or soybean meal in diets for Atlantic salmon (Salmo salar) Effect on growth performance, nutriente digestibility, carcass composition, gut health, and physical feed quality. Aquaculture, v.288, p.305311, 2009.

QUINTERO-PINTO, L.G.; PEZZATO, L.E.; GAMBOA, B.S.P.; ARAÚJO, D.M. Digestibilidade de fontes proteicas e disponibilidade de fosfatos inorgânicos em três fases de desenvolvimento da Tilápia-do-Nilo. Bol. Inst. Pesca, v.43, p.1-13, 2017.

RAMOS, A.P.S.; BRAGA, L.G.T.; CARVALHO, J.S.O.; OLIVEIRA, S.J.R. Digestibility of agro-industrial by products in 200 and 300-g Nile tilápia. Rev. Bras. Zootec., v.41, p.462-466, 2012.
RODRIGUES, A.P.O. Nutrição e alimentação do tambaqui (Colossoma macropomum). Bol. Inst. Pesca, v.40, p.135-145, 2014.

SAS®. SAS® University edition. Cary, NC: SAS Institute Inc., 2017.

SILVA, D.J., QUEIROZ, A.C. Análise de alimentos: métodos químicos e biológicos. 3.ed. Viçosa: UFV, 2002. 235p.

SILVA, J.A.M.; PEREIRA FILHO, M.; OLIVEIRA-PEREIRA, M.I. Frutos e sementes consumidos pelo Tambaqui, Colossoma macrompum (Cuvier, 1818) incorporados em rações. digestibilidade e velocidade de trânsito pelo trato gastrointestinal. Rev. Bras. Zootec., v.32, p.1815-1824, 2003.

SINHA, A.K.; KUMAR, V.; MAKKAR, H.P.; DE BOECK, G.; BECKER, K. Non-starch polysaccharides and their role in fish nutrition - a review. Food Chem., v.127, p.1409-1426, 2011.

SOARES, K.J.A.; RIBEIRO, F.B.; BOMFIM, M.A.D.; MARCHÃO, R.S. Valor nutricional de alimentos alternativos para tambaqui (Colossoma macropomum). Arch. Zootec., v.66, p.491-497, 2017.

VÁSQUEZ-TORRES， W.; YOSSA， M.I.; GUTIÉRREZ-ESPINOSA, M.C. Digestibilidad aparente de ingredientes de origen vegetal y animal en la cachama. Pesqui. Agropecu. Bras., v.48, p.920-927, 2013. 